\section{Complications of Carotid Angioplasty and Stenting}

I would like to highlight some important aspects of the article by Baldi et al, "Carotid Artery Stent Placement without Angioplasty and Cerebral Protection: A Single-Center Experience with up to 7 Years' Follow-Up."1

The literature devoted to the treatment of carotid artery stenosis is considerable, but virtually all articles refer to stent plus angioplasty. In discussing the complications, the authors never pinpointed the origin. Was it from balloon dilation (always traumatic) or stent placement?

I am convinced that carotid artery stenosis can be treated by selfexpanding stents alone, carrying fewer risks for patients. Preliminary patient selection is essential, preferably with CT angiography, because circumferential calcifications prevent stent expansion and should be considered a surgical indication or, less appropriately, an indication for angioplasty, which will, however, be highly traumatic.
Our experience was reported in an article similar to that of Baldi et al. ${ }^{2}$

\section{References}

1. Baldi S, Zander T, Rabellino M, et al. Carotid artery stent placement without angioplasty and cerebral protection: a single-center experience with up to 7 years' follow-up. AJNR Am J Neuroradiol 201 1;32:759-63

2. Leonardi M, Dall'Olio M, Raffi L, et al. Carotid stenting without angioplasty and without protection: the advantages of a less invasive procedure. Interv Neuroradiol 2008;14:153-63

M. Leonardi Department of Neuroradiology University of Bologna Ospedale Bellaria Bologna, Italy

http://dx.doi.org/10.3174/ajnr.A3213 